\title{
Which traits predict elevated distress during the Covid-19 pandemic? \\ Results from a large, longitudinal cohort study with psychiatric patients and healthy controls
}

Katharina Brosch ${ }^{a, b}$, Tina Meller ${ }^{a, b}$, Julia-Katharina Pfarr ${ }^{a, b}$, Frederike Stein ${ }^{a, b}$, Simon

Schmitt $^{a, b}$, Kai G. Ringwald ${ }^{a, b}$, Lena Waltemate ${ }^{c}$, Hannah Lemke ${ }^{c}$, Katharina Thiel ${ }^{c}$, Elisabeth Schrammen ${ }^{c}$, Carina Hülsmann ${ }^{c}$, Susanne Meinert ${ }^{c}$, Katharina Dohm ${ }^{c}$, Elisabeth J. Leehr ${ }^{c}$, Nils Opel ${ }^{c, d}$, Axel Krug $^{\mathrm{a}, \mathrm{e}}$, Udo Dannlowski $^{\mathrm{c}}$, Igor Nenadić ${ }^{\mathrm{a}, \mathrm{b}}$, Tilo Kircher $^{\mathrm{a}, \mathrm{b}}$

a Department of Psychiatry and Psychotherapy, Philipps-Universität Marburg and University Hospital Marburg, UKGM, Rudolf-Bultmann-Str. 8, 35039 Marburg, Germany

${ }^{\mathrm{b}}$ Center for Mind, Brain and Behavior (CMBB), Hans-Meerwein-Str. 6, 35032 Marburg, Germany

${ }^{c}$ Department of Psychiatry, Westfälische Wilhelms-Universität Münster, AlbertSchweitzer-Campus 1, Building A9a, 48149 Münster, Germany

d Interdisciplinary Centre for Clinical Research, IZKF, University of Münster, Germany

e Department of Psychiatry and Psychotherapy, University of Bonn, Bonn, Germany

Running title: Which traits predict elevated distress during the Covid-19 pandemic?

Corresponding author: Katharina Brosch, M.Sc.

Department of Psychiatry and Psychotherapy

Philipps-Universität Marburg

Rudolf-Bultmann-Str. 8

35039 Marburg, Germany

Phone: +49-6421-58 61953

Email: brosch@staff.uni-marburg.de

Word count: 3978 
medRxiv preprint doi: https://doi.org/10.1101/2021.04.01.21254625; this version posted April 5, 2021. The copyright holder for this preprint (which was not certified by peer review) is the author/funder, who has granted medRxiv a license to display the preprint in perpetuity.

It is made available under a CC-BY-NC-ND 4.0 International license .

\section{Abstract}

Background: The Covid-19 pandemic resulted in repeated, prolonged restrictions in daily life. Social distancing policies as well as health anxiety are thought to lead to mental health impairment. However, there is lack of longitudinal data identifying atrisk populations particularly vulnerable for elevated Covid-19-related distress.

Methods: We collected data of $N=1268$ participants ( $n=622$ healthy controls $(\mathrm{HC})$, and $n=646$ patients with major depression, bipolar disorder, schizophrenia or schizoaffective disorder) at baseline (2014-2018) and during the first lockdown in Germany (April-May 2020). We obtained information on Covid-19 restrictions (number and subjective impact of Covid-19 events), and Covid-19-related distress (i.e., subjective fear and isolation). Using multiple linear regression models including trait variables and individual Covid-19 impact, we sought to predict Covid-19-related distress.

Results: HC and patients reported similar numbers of Covid-19-related events, and similar subjective impact rating. They did not differ in Covid-19-related subjective fear. Patients reported significantly higher subjective isolation. $30.5 \%$ of patients reported worsened self-rated symptoms since the pandemic. Subjective fear in all participants was predicted by four variables: trait anxiety (STAI-T), conscientiousness (NEO-FFI), Covid-19 impact, and sex. Subjective isolation in HC was predicted by social support (FSozu), Covid-19 impact, age, and sex; in patients, it was predicted by social support and Covid-19 impact.

Conclusion: Our data shed light on differential effects of the pandemic in psychiatric patients and HC. They identify relevant, easy-to-obtain variables for risk profiles related to interindividual differences in Covid-19-related distress for direct translation into clinical practice.

Keywords: Covid-19, mental health, stress, Big Five, social support 


\section{Introduction}

The Covid-19 pandemic and its ramifications can be considered a global stressor (Kaye-Kauderer, Feingold, Feder, Southwick, \& Charney, 2021). The impact of stressors on mental health depend on stressor characteristics, as well as traits of the exposed individuals (Alisic et al., 2014; Hensley \& Varela, 2008; Kendler, Gatz, Gardner, \& Pedersen, 2006; Marin et al., 2011). The Covid-19 pandemic has generated a qualitatively new challenge (Johns Hopkins University, https://coronavirus.jhu.edu/map.html).

Social distancing, a commonly implemented measure to limit virus spread, has put large parts of the population in social isolation for a prolonged period (Kira et al. 2020). This might also restrict availability of social support systems, including access to mental health care, leading to increased stressor load (Banerjee \& Rai, 2020; Mancini, 2020). Social isolation is known to affect mental and physical health negatively, with effect sizes similar to premature mortality in hypertension and hyperglycaemia (Aleman \& Sommer, 2020; Holt-Lunstad, Smith, Baker, Harris, \& Stephenson, 2015; Holt-Lunstad, Smith, \& Layton, 2010; J. Wang et al., 2017). Experts have warned that using social isolation as a strategy to contain the Covid-19 pandemic could result in a future mental-health pandemic, including increased suicide risk ("Keep mental health in mind," 2020; Parrish, 2020; Reger, Stanley, \& Joiner, 2020). In previous, smaller epidemics, such as severe acute respiratory syndrome (SARS), an increase in suicides was reported especially in elderly adults, which was associated with social isolation and anxiety (Yip, Cheung, Chau, \& Law, 2010). First data from Japan show a $16 \%$ increase in suicides following the second wave of the Covid-19 pandemic (July-October 2020) (Tanaka \& Okamoto, 2021).

Even though lockdown restrictions and infection rates vary across countries, current Covid-19 cross-sectional studies suggest elevated stress and negative affect 
increase across the general population worldwide. In a recent study in the Mexican population $(N=1,105)$, half of the participants $(50.3 \%)$ reported moderate to severe levels of psychological distress due to Covid-19, as well as $22.6 \%$ reporting moderate to severe symptoms of anxiety (Cortés-Álvarez, Piñeiro-Lamas, \& Vuelvas-Olmos, 2020). In an American representative sample $(N=10,368)$, more than $25 \%$ reported moderate to severe anxiety symptoms associated with the pandemic (Fitzpatrick, Harris, \& Drawve, 2020). A review of four studies in the Chinese general population consistently found increased symptoms of anxiety and depression, as well as selfreported stress (Rajkumar, 2020). In another large cross-sectional study of the general Chinese population $(N=56,679)$, participants reported several mental health symptoms, including depressive symptoms (27.9\%), anxiety symptoms (31.6\%), insomnia (29.2\%), and acute stress symptoms (24.4\%) (Shi et al., 2020). Reviewing 25 longitudinal studies and natural experiments in a meta-analysis, Prati and Mancini (2021) report a small, but highly heterogenous effect of lockdown measures on mental health across studies, and stress the need for further investigation of subgroups which might be at particular risk for adverse mental health effects.

Two meta-analyses reviewing mostly cross-sectional studies (up to May 2020) identified female gender, younger age ( $\leq 40$ years), social isolation, and presence of chronic/psychiatric illness, among others, as risk factors for increased mental distress during the pandemic (Luo, Guo, Yu, \& Wang, 2020; Xiong et al., 2020). Indeed, individuals with previous or current mental health problems constitute a vulnerable group, as (psychosocial) stressors are known to exacerbate existing symptoms of major depression (Burke, Davis, Otte, \& Mohr, 2005; Kendler, Karkowski, \& Prescott, 1999). The additional stress of the pandemic with concomitant social isolation might be particularly detrimental to individuals already at poor mental health. In a recent case-control study, psychiatric patients were shown to report higher worries about 
physical health, as well as higher anger and impulsivity symptoms compared to healthy controls during the pandemic (Hao et al., 2020).

While cross-sectional studies provide data of the impact on mental health across multiple populations, they lack longitudinal assessments that are better suited to examine the complex relationship between current and pre-pandemic mental health status. Indeed, Shanahan et al., (2020) showed that distress preceding the pandemic was the strongest predictor of emotional distress during the pandemic itself.

In this study, we analysed data on Covid-19 impact and subjective distress in an ongoing large longitudinal German bi-centre cohort, including patients with affective and psychotic disorders, and healthy individuals (Kircher et al., 2018). Participants of this unique large cohort had been deeply phenotyped, including structured diagnostic assessment, before the pandemic, and were now re-assessed after exposure to social distancing and isolation measures implemented during the lockdown in Germany. Trait markers, indicative of risk for mental distress or disorders, might modulate individual level of Covid-19 distress. Based on the literature, we selected eleven variables previously associated with mental health problems which are relatively stable across time, i.e.: childhood maltreatment, familial risk, social support, resilience, IQ, trait anxiety, and the Big Five personality traits (i.e. openness, conscientiousness, extraversion, agreeableness, neuroticism) (See Table 1). This allowed us to test 1 ) how Covid-19 restrictions impact $\mathrm{HC}$ and patients, and 2) which baseline variables predict Covid-19 distress. 


\section{Method}

\section{Sample description}

The DFG FOR2107 cohort is a bi-centre, longitudinal study investigating healthy controls (HC), and patients with MDD, bipolar disorder (BP), schizophrenia (SZ), and schizoaffective disorder (SZA) (Kircher et al., 2018). The study was approved by the ethics committees of the universities of Marburg and Münster, Germany, in accordance with the Declaration of Helsinki. Baseline data used in this study were collected in Marburg and Münster from 2014 - 2018, with a median of data collected in 2016 (36.6\%), four years before the Covid-19 telephone interview in 2020 was conducted.

From April - May 2020, during the first lockdown in Germany, we contacted $n=1928$ individuals who had previously participated in baseline testing. Of these, $n=526$ could not be contacted, and $n=134$ did not want to participate in the telephone survey, thus leaving a final sample of $N=1268$ (65.5\% female; HC $n=622$, patients $n=646$; MDD $n=514$, BD $n=74$, SZ $n=33$, SZA $n=25)$. Based on the literature, we chose eleven traits associated with mental health outcomes: Big Five (NEO-FFI), social support (FSozu), IQ (MWT-B), childhood maltreatment (CTQ), familial risk (assessed using a questionnaire), resilience (RS-25), and trait anxiety (STAI-T) (Costa \& McCrae, 1992; Fydrich, Sommer, \& Braehler, 2007; Laux, Glanzmann, Schaffner, \& Spielberger, 1981; Lehrl, 2005; Leppert, Koch, Brähler, \& Strauß, 2008; Wingenfeld et al., 2010). Table 2 lists sociodemographic and test data at baseline.

\section{Data collection}

Social distancing measures and formal regulations issued by the German Federal Government on March 22 ${ }^{\text {nd }}$, 2020 included severe reductions of interpersonal contacts in both social (e.g., closing of gathering places, restrictions in meeting 
people) and occupational areas of daily life (e.g., closing of schools, working from home). The restrictions were in place during the entire data collection process.

We obtained lockdown data from April $7^{\text {th }}, 2020$ - May $8^{\text {th }}, 2020$. Trained research assistants conducted 20-minute semi-structured telephone interviews. The team was briefed to provide information about help hotlines if participants reported increased psychiatric symptoms due to Covid-19. We assessed Covid-19 impact through selfreport of Covid-19-related incidents (Table 3). Covid-19 distress was operationalized as Covid-19-related subjective fear and isolation (Table 4). Covid-19-related incidents included 11 types of events, i.e. quarantine, working from home, loss of recreational activities, cancellation of private travel, cancellation of work travel, loss of childcare options, paused studies at school or university, restrictions in health care, pecuniary damage, short-time work, and loss of job. If participants had experienced such an incident, they were asked to rate its valence (positive or negative) and intensity ( $0-5$ Likert-scales, with higher scores indicating higher intensity). Covid-19 impact was calculated by adding all intensity-related ratings, irrespective of their perceived valence. Negative Covid-19 impact rating and positive Covid-19 impact rating were calculated by only adding intensity ratings for either negatively, or positively rated items, respectively. This was based on scoring done in the life event questionnaire (LEQ) (Norbeck, 1984). In addition, all participants were asked to give information regarding their work situation (type of employment) in January 2020, before restrictions were implemented in Germany.

To better understand the impact of Covid-19 in the domain of health, we interviewed participants whether they themselves or associated persons (partner, core family, or friends) were subject to one or more of the following health events: testing positive for Covid-19, experiencing quarantine, contact to a Covid-19 positive person, any inpatient treatment, intensive-care treatment, or death due to Covid-19. 
To assess participants' subjective distress during the pandemic, we obtained selfreport ratings of Covid-19-related subjective fear (subjective fear) and Covid-19related subjective isolation (subjective isolation). Subjective fear was calculated by adding the ratings of three items "fear of Covid-19 regarding own health", "fear of Covid-19 regarding health of associated persons", and "fear of Covid-19-related economic and social consequences", each rated on a six-point-Likert scale. Subjective isolation was assessed by prompting participants to think about current lockdown restrictions and then to answer three items of the revised UCLA loneliness scale ("There is no one I can turn to", "I feel left out", and "I feel isolated from others"), rated on a four-point-Likert scale (Russell, Peplau, \& Cutrona, 1980). Subjective isolation was calculated by summing up the three items. Cronbach's alpha for this scale was $\alpha=.684$.

Patients were additionally asked to rate subjective changes in psychopathological symptom severity since the beginning of the pandemic (improved, unchanged, a little worse, substantially worse) as well as constraints regarding access to psychiatric/psychological care (see Table 5).

\section{Statistical analyses}

Significance level was set at $a<.05$. Analyses were performed using SPSS 27 statistical software (IBM Corp.). Figures were designed using Microsoft Excel (Version 16.46) and ggplot2 running under R (Version 4.0.3) (Microsoft Corporation, 2018; R Core Team, 2020; Wickham, 2018). To compare mean scores between patients and healthy controls, two-tailed, independent sample t-tests were used. As Levene's test for equality of variances was found to be violated for subjective isolation and fear, we report t-statistics not assuming homogeneity of variance for these. Frequency distributions were analysed using chi-square tests. As baseline 
data on remission status were missing for $n=42$ patients, and symptom change data were missing for $n=16$, we report the number of data sets used for each analysis. Patients with unchanged, improved, and worsened symptoms were compared using ANOVA.

Multiple regression analyses were applied to predict Covid-19 distress (i.e. Covid-19related fear and isolation) from the eleven baseline variables, age, sex, site, and Covid-19 impact. Subjective fear was additionally predicted using diagnosis. We predicted subjective fear in the entire sample, while we ran multiple regression analyses for subjective isolation in $\mathrm{HC}$ and patients separately (as they differed significantly in this measure). For the multiple regressions, we performed Bonferroni correction for multiple testing, adjusting $p$-values for three tests. No multicollinearity was present (see Supplement, Table 1-3). 


\section{Results}

\section{Impact of Covid-19 restrictions on $\mathrm{HC}$ and patients}

$18.6 \%$ of the participants reported mandated quarantine either for themselves, or of an associated person (partner, family member or friend). Regarding Covid-19-related incidents, only 36 participants $(2.9 \%)$ did not experience any event, the median of Covid-19 incidents experienced was 3. Patients and HC did not differ in the number of Covid-19 incidents experienced $(t(1239)=1.02, p=.308, d=1.68)$, nor in their positive Covid-19 impact rating $(t(1266)=0.162, p=.871, d=2.12)$, or negative Covid19 impact rating $(t(1266)=1.657, p=.097, d=5.21)$, and neither in their total Covid-19 impact rating $(t(1266)=1.591, p=.109, d=5.64)$.

Regarding Covid-19 distress, patients did not differ significantly in subjective fear compared to $\mathrm{HC}(t(1254.22)=-1.44, p=.152, d=5.27)$. However, patients reported significantly higher subjective isolation, $t(1183.57)=-10.16, p<.001 ; d=2.12$. 


\section{Figure 1}

Subjective Covid-19 distress during lockdown in patients and HC
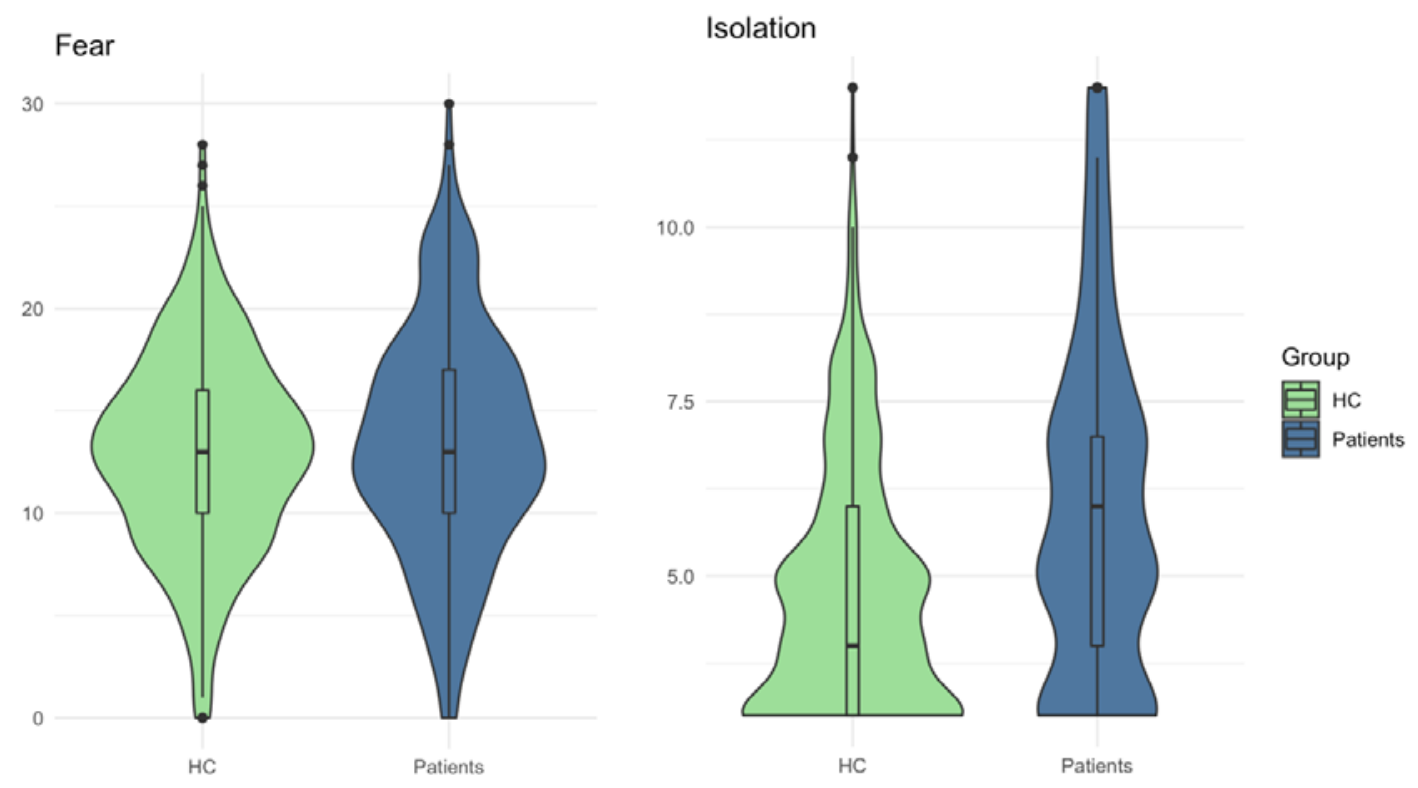

Note: Higher values indicate higher subjective isolation/fear. Patients and healthy controls $(\mathrm{HC})$ do not differ significantly in subjective fear (range: 0-30), but in subjective isolation (range: $3-12$ ).

$27.9 \%$ of patients reported Covid-19-related problems in obtaining treatment options, of which $21.4 \%$ reported changes in therapy (Table 5).

Half of patients $(51.1 \%)$ in our sample reported no psychiatric symptoms directly before the beginning of the pandemic. However, almost one third of patients $(n=192$, $30.5 \%$ ) reported small to substantial symptom aggravation since the beginning of the pandemic, while $10.3 \%$ of the patient sample reported improved symptoms, and more than half of the sample $(59.2 \%)$ reported no change in symptom severity (Table 5).

Based on changes in symptom severity, patients were split into three subgroups with unchanged, improved, or worsened symptom load (See Figure 2, and Table 6). 
Table 6 lists differences in the three symptom change groups. Patients reporting worsened symptoms since pandemic onset did not statistically differ from those with improved or unchanged symptoms with regard to the baseline variables: diagnosis $\left(X^{2}(6)=3.42, p=.755\right)$, treatment state $\left(X^{2}(4)=4.57, p=.334\right)$, or recurrence status of $\operatorname{MDD}\left(X^{2}(2)=4.62, p=.099\right)$. They did not differ in number of Covid-19-related incidents during the pandemic $(p=.095)$, however, they differed significantly in their negative Covid-19 impact rating $\left(F(2,627)=12.53, p<.001, \eta^{2}=.038\right)$, positive Covid-19 impact rating $\left(F(2,627)=4.10, p=.017, \eta^{2}=.013\right)$, and their total Covid-19 impact rating $\left(F(2,627)=7.16, p=.001, \eta^{2}=.022\right)$.

The groups also differed significantly in both measures of subjective Covid-19 distress, i.e., subjective fear $(F(3,642)=6.58, \quad p<.001)$, and subjective isolation: $F(2,629)=38.26, p<.001$. (See Table 6). 


\section{Figure 2}

Symptom changes in patients since beginning of pandemic and pre-pandemic mood state

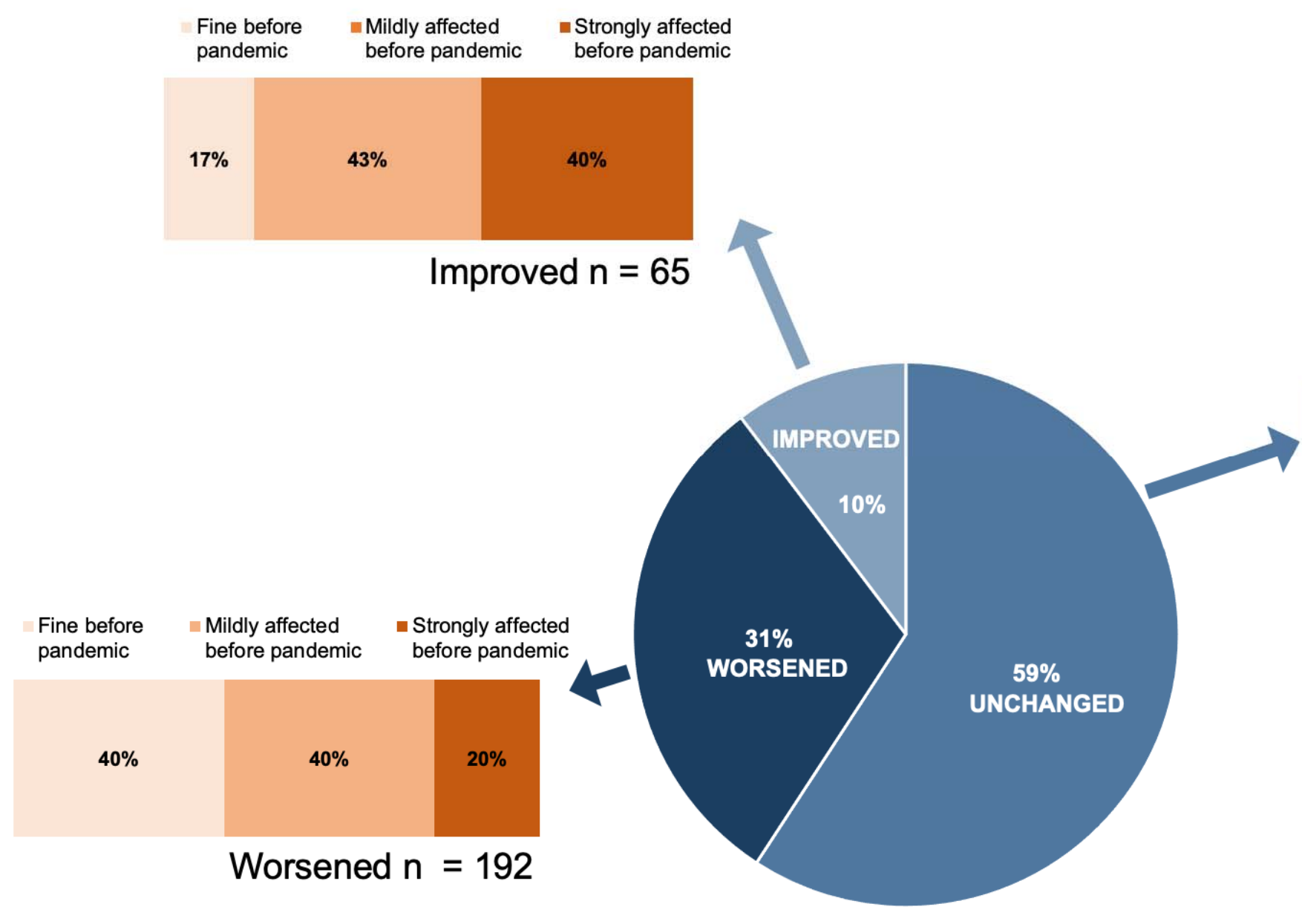

Fine before

pandemic

Mildly affected

before pandemic

-

Strongly affe

before pandemet

表.

$65 \%$

$23 \%$

Unchanged $n=373$
Fine before pandemic

Mildly affected before pandemic

trongly affecte efore pandemic

$40 \%$

Worsened $\mathrm{n}=192$ 


\section{Regression models predicting Covid-19 distress using baseline data}

Subjective fear was statistically significantly predicted by the model, $F(16,1208)=4.71, p<.001, R^{2}=.06\left(\operatorname{adj} . R^{2}=.05\right)$, indicative of a weak goodness-of-fit (Cohen, 1988). Higher trait anxiety $\left(\beta=.185, p_{\mathrm{adj}}=.006\right)$, higher Covid-19 impact $\left(\beta=.130, p_{\mathrm{adj}}<.001\right)$, lower conscientiousness $\left(\beta=.111, p_{\mathrm{adj}}=.004\right)$, and $\operatorname{sex}(\beta=.078$, $\left.p_{\text {adj }}=.020\right)$ significantly predicted higher subjective Covid-19 fear. The other variables did not predict subjective fear (i.e., diagnosis, age, site, childhood maltreatment, social support, openness, extraversion, agreeableness, neuroticism, resilience, IQ, familial risk; adj. ps >.05) (See Supplement Table 1).

As subjective isolation differed statistically in $\mathrm{HC}$ and patients, we analysed multiple regression models for $\mathrm{HC}$ and patients independently. In $\mathrm{HC}$, subjective isolation was significantly predicted by the model: $F(15,582)=8.17, R^{2}=.17$ (adj. $\left.R^{2}=.15\right)$, indicative of a moderate goodness-of-fit (Cohen, 1988). Lower social support ( $\beta=-.194$, $\left.p_{\mathrm{adj}}<.001\right)$, sex $\left(\beta=.161, p_{\mathrm{adj}}<.001\right)$, lower age $\left(\beta=-.177, p_{\mathrm{adj}}<.001\right)$, and higher Covid19 impact $\left(\beta=.131, p_{\mathrm{adj}}=.002\right)$ predicted higher subjective isolation in $\mathrm{HC}$. The other variables did not predict subjective isolation in $\mathrm{HC}$ (i.e., site, childhood maltreatment, trait anxiety, Big Five, resilience, IQ, familial risk, all adj. ps >.05), see Supplement (Table 2).

In patients, subjective isolation was significantly predicted by the model, $F(15,610)=9.99, p<.001, R^{2}=.20\left(\operatorname{adj} . R^{2}=.18\right)$, indicative of a moderate goodness-offit (Cohen, 1988). In patients, higher Covid-19 impact $\left(\beta=-.114, p_{\mathrm{adj}}=.006\right)$, and lower social support $\left(\beta=-.269, p_{\mathrm{adj}}<.001\right)$ predicted higher subjective isolation. The other variables (i.e., age, sex, site, childhood maltreatment, trait anxiety, Big Five, resilience, IQ, and familial risk; adj. ps >.05) did not predict subjective isolation in 
patients. Summaries of the entire models can be found in the Supplement (Table 13).

Using the identified variables for Covid-19 distress (i.e., trait anxiety, Covid-19 impact, conscientiousness, sex, and social support), we re-examined scores in improved, unchanged, and worsened patient groups. We found significantly different sex distribution in these groups, and significantly higher trait anxiety in the worsened group (See Table 6). Patient symptom change groups did neither differ significantly in conscientiousness and social support, nor in Covid-19 impact (see Table 6 and Table 4). Table 4 in the Supplement lists additional patient group characterization by diagnosis. 
medRxiv preprint doi: https://doi.org/10.1101/2021.04.01.21254625; this version posted April 5, 2021. The copyright holder for this preprint

\section{Discussion}

Based on a large longitudinal, transdiagnostic, bi-centre cohort of patients with mental disorders and healthy subjects, our study provides evidence for a disproportionately stronger subjective isolation effect in psychiatric patients, compared to HC, despite similar number of Covid-19-related events and similar impact rating in $\mathrm{HC}$ and patients.

We identified several variables (social support, trait anxiety, conscientiousness, sex, age) associated with Covid-19 distress in $\mathrm{HC}$ and patients. These findings point to prolonged stress associated with social isolation. We identified risk populations within the general population and those suffering from mental disorders, for which targeted interventions are warranted.

First, our findings demonstrate that patients are at particular risk for higher subjective isolation when exposed to social distancing schemes. Possible reasons for this might include general or non-specific elevation of stress in a society, in addition to lack of resilience, resources, and reduced availability of psychiatric support. Such effects have been demonstrated in both adults and adolescents, usually not in cohorts that have had previous clinical characterization for pre-Covid disease courses (Loades et al., 2020; Riehm et al., 2020). Our findings align with two meta-analyses identifying psychiatric patients as at-risk for increased mental distress during the pandemic (Luo et al., 2020; Xiong et al., 2020). It is possible that healthy individuals have more resources for emotional/social support at their disposal (as indicated by higher baseline social support) that buffered the negative effects of these incidents and prevented higher feelings of isolation (Hoefnagels, Meesters, \& Simenon, 2007). $30.5 \%$ of our patients reported worsened symptoms since the pandemic. This group of patients also rated Covid-19-related incidents more negatively, less positively, and reported higher subjective isolation and -fear compared to the other patient groups. 
Restoring sufficient patient care might be one important aspect in improving symptom load (as problems in this area were reported by $27.9 \%$ of all patients). In the general population, more than one third of adults with serious distress during the pandemic listed inability to obtain health care as a contributing factor for increased distress, further highlighting the need to facilitate (physical and mental health) treatment attainment (McGinty, Presskreischer, Anderson, Han, \& Barry, 2020).

Second, using baseline data, we were able to predict Covid-19 distress, i.e., subjective fear and isolation. Higher subjective fear was significantly predicted by higher trait anxiety, higher Covid-19 impact, lower conscientiousness, and female sex in $\mathrm{HC}$ and psychiatric patients (in order of predictive strength, see Supplement). However, these variables only explained $6 \%$ of variance in subjective fear. Other current factors, such as media consumption and catastrophic cognitions about Covid19 might also influence subjective fear, but were not assessed in this study (Bendau et al., 2020; Rosebrock et al., 2021).

Interestingly, the patient group reporting worsened symptoms since the pandemic also reported significantly higher trait anxiety scores than the unchanged and improved groups. Trait anxiety might not only be associated with subjective fear of Covid-19, but also with worse mental health outcomes during the pandemic in general. This aligns with previous findings reporting an association between depressive symptoms and perceived risk of Covid-19 infection (Kim, Nyengerai, \& Mendenhall, 2020).

As subjective isolation differed significantly between $\mathrm{HC}$ and patients, we ran two independent multiple regression models. In patients, subjective isolation was predicted by social support and Covid-19 impact. In HC, it was predicted by the same factors as patients, but additionally by age (inversely) and sex. 
In line with our findings, female gender has been repeatedly associated with poorer mental health outcomes during the pandemic (Luo et al., 2020; Vindegaard \& Benros, 2020; Xiong et al., 2020). In patients, sex did not reach significance after correcting for multiple tests $(p=.051)$ but might also contribute to subjective isolation in patients.

Our findings show that besides Covid-19 impact, trait variables such as social support (and additionally age and sex in $\mathrm{HC}$ ) contribute to subjective isolation during the pandemic, with models accounting for $15 \%$ of variance in $\mathrm{HC}$, and $18 \%$ of variance in patients. Previous social support seems to be important in feeling connected and less isolated during the pandemic. Our findings align with findings by Gloster et al., (2020), who identified social support as a strong predictor for mental health outcomes during the pandemic.

It is noteworthy that social support data, collected 2-6 years prior were still relevant for subjective isolation. Social isolation during the pandemic has also been associated with poorer life satisfaction, and higher levels of substance use (Clair, Gordon, Kroon, \& Reilly, 2021). Current social support during the pandemic was found to be associated with fewer depressive symptoms, with quality of contact being more important than quantity (Sommerlad et al., 2021). Higher social support was also associated with more positive appraisal and higher resilience during the pandemic (Veer et al., 2021). In light of these findings, social support seems to be relevant for both $\mathrm{HC}$ and patients in the maintenance of mental health during a pandemic.

In the aftermath of traumatic events, a "pulling together effect" is often described, with an increase in social support and cohesion in the affected population. This effect was shown to buffer negative effects of such traumatic events (Mancini, 2020; Reger et al., 2020). However, with increased levels of social isolation, especially in patients, 
this effect does not seem to be present during this pandemic. This might be explained by the difference between singular traumatic events (e.g., natural disasters, terrorist attacks) compared to prolonged or even ongoing stressors. The specific characteristics of this pandemic and the very strategies (i.e., social distancing) to ameliorate its adverse effects seem to impede the protective effect of increased social cohesion. As social distancing is used to contain virus spread, we as a society have to act counter-intuitively than we would otherwise in stressful situations: as opposed to finding emotional and physical comfort from our social networks, we are asked to limit social contacts and to engage in socially distanced communication with friends and family. Despite large-scale efforts to minimize social (as opposed to physical) distancing, e.g. through the use of web-based communication, these might not overcome the lack of physical proximity to other humans, which has shown significant benefits to mental and physical health (Jakubiak \& Feeney, 2019; Thomas \& Kim, 2020). This indicates that individual efforts, and new and creative strategies to keep in touch are not sufficient (or not sufficiently used) to offset feelings of isolation. Social isolation is well known to be detrimental to both physical as well as mental health, and constitutes an important risk factor for MDD (Holt-Lunstad et al., 2015; Qiu et al., 2020). Feelings of isolation might add up over time with detrimental effects to mental health, and generate considerable clinical burden.

To counteract isolation during the pandemic, it seems vital to increase social integration and to immunize isolated individuals against the negative impact of restrictions to contain virus spread. Future policies should therefore address the problem of loneliness and isolation and focus on interventions that target feelings of isolations in population groups already experiencing lesser degrees of social integration, and provide safe options for social interaction during the pandemic. Our 
results point to social support as an important starting point for targeted interventions and preventions.

\section{Limitations}

Several limitations should be noted. The current study did not include a full diagnostic interview at mid-pandemic follow-up, only one conducted for baseline data collection. More objective measures, including HAMD scores, assessed by trained raters and indepth interviews would have improved the validity of the findings.

We did not re-assess trait anxiety and social support during the pandemic. It might be argued that subjective fear and subjective isolation are simple expressions of these traits, manifesting irrespectively of the pandemic. However, in all three multiple regression models, Covid-19 impact was a significant predictor for subjective fear and isolation. Covid-19-related fear and isolation ratings seem to be influenced by both baseline trait variables (trait anxiety and social support), but also by Covid-19 impact. The found associations cannot be regarded as causal inferences, however, they might guide future research and hint at possible risk factors.

We asked patients about subjective symptom changes between two time points, between January 2020 before the pandemic, and current symptoms during lockdown. While self-ratings are known to be associated with clinicians' ratings of severity, it is still possible that current symptom load might have influenced symptom severity assessment of January 2020 (Tondo, Burrai, Scamonatti, Weissenburger, \& Rush, 1988).

\section{$\underline{\text { Outlook }}$}


The Covid-19 pandemic constitutes an unfamiliar challenge to individuals and societies worldwide. With ongoing or intermittent lockdowns set in place, policy makers should acknowledge the mental health impact of social isolation, which might be even more pronounced in the long-term (Daly, Sutin, \& Robinson, 2020). Targeted prevention and interventions, especially in those populations at particular risk should be considered (Saltzman, Hansel, \& Bordnick, 2020). The lack of such interventions might result in significant and lasting impact on mental health burden, in people previously affected by mental health impairments, as well as those without a prior history of mental illness (Galea, Merchant, \& Lurie, 2020). 


\section{Acknowledgments}

This work is part of the German multicentre consortium "Neurobiology of Affective

Disorders. A translational perspective on brain structure and function“, funded by the German Research Foundation (Deutsche Forschungsgemeinschaft DFG; Forschungsgruppe/Research Unit FOR2107).

We are deeply indebted to all study participants and staff. A list of acknowledgments can be found here: for2107.de/acknowledgements.

\section{Conflicts of interest}

Biomedical financial interests or potential conflicts of interest: Tilo Kircher received unrestricted educational grants from Servier, Janssen, Recordati, Aristo, Otsuka, neuraxpharm. All other authors declare no conflict of interest.

\section{Ethical standards}

The authors assert that all procedures contributing to this work comply with the ethical standards of the relevant national and institutional committees on human experimentation and with the Helsinki Declaration of 1975, as revised in 2008. 


\section{References}

Aleman, A., \& Sommer, I. (2020). The Silent Danger of Social Distancing.

Psychological Medicine, 9-10. https://doi.org/10.1017/S0033291720002597

Alisic, E., Zalta, A. K., Van Wesel, F., Larsen, S. E., Hafstad, G. S., Hassanpour, K., \& Smid, G. E. (2014). Rates of post-traumatic stress disorder in trauma-exposed children and adolescents: Meta-analysis. British Journal of Psychiatry.

https://doi.org/10.1192/bjp.bp.113.131227

Banerjee, D., \& Rai, M. (2020). Social isolation in Covid-19: The impact of loneliness. International Journal of Social Psychiatry, 66(6), 525-527. https://doi.org/10.1177/0020764020922269

Bendau, A., Petzold, M. B., Pyrkosch, L., Mascarell Maricic, L., Betzler, F., Rogoll, J., ... Plag, J. (2020). Associations between COVID-19 related media consumption and symptoms of anxiety, depression and COVID-19 related fear in the general population in Germany. European Archives of Psychiatry and Clinical Neuroscience. https://doi.org/10.1007/s00406-020-01171-6

Burke, H. M., Davis, M. C., Otte, C., \& Mohr, D. C. (2005). Depression and cortisol responses to psychological stress: A meta-analysis. Psychoneuroendocrinology, 30(9), 846-856. https://doi.org/10.1016/j.psyneuen.2005.02.010

Carfì, A., Bernabei, R., \& Landi, F. (2020). Persistent Symptoms in Patients after Acute COVID-19. JAMA - Journal of the American Medical Association. https://doi.org/10.1001/jama.2020.12603

Chambers, J. A., Power, K. G., \& Durham, R. C. (2004). The relationship between trait vulnerability and anxiety and depressive diagnoses at long-term follow-up of Generalized Anxiety Disorder. Journal of Anxiety Disorders, 18(5), 587-607. https://doi.org/10.1016/j.janxdis.2003.09.001

Clair, R., Gordon, M., Kroon, M., \& Reilly, C. (2021). The effects of social isolation on 
well-being and life satisfaction during pandemic. Humanities and Social Sciences

Communications. https://doi.org/10.1057/s41599-021-00710-3

Cohen, J. (1988). Statistical power for the social sciences. Hillsdale, NJ: Laurence

Erlbaum and Associates.

Cortés-Álvarez, N. Y., Piñeiro-Lamas, R., \& Vuelvas-Olmos, C. R. (2020).

Psychological effects and associated factors of COVID-19 in a Mexican sample.

Disaster Medicine and Public Health Preparedness, 1-27.

https://doi.org/10.1017/dmp.2020.215

Costa, P. T., \& McCrae, R. R. (1992). Revised NEO personality inventory (NEO-PI-R)

and NEO five-factor inventory (NEO-FFI). Odessa FL Psychological Assessment

Resources.

Daly, M., Sutin, A., \& Robinson, E. (2020). Longitudinal changes in mental health and the COVID-19 pandemic: Evidence from the UK Household Longitudinal Study. Psychological Medicine. https://doi.org/10.1017/S0033291720004432

DeNeve, K. M., \& Cooper, H. (1998). The Happy Personality: A Meta-Analysis of 137

Personality Traits and Subjective Well-Being. Psychological Bulletin.

https://doi.org/10.1037/0033-2909.124.2.197

Der, G., Batty, G. D., \& Deary, I. J. (2009). The association between IQ in adolescence and a range of health outcomes at 40 in the 1979 US National Longitudinal Study of Youth. Intelligence.

https://doi.org/10.1016/j.intell.2008.12.002

Fitzpatrick, K. M., Harris, C., \& Drawve, G. (2020). Fear of COVID-19 and the Mental Health Consequences in America. Psychological Trauma: Theory, Research, Practice, and Policy, 12, 17-21. https://doi.org/10.1037/tra0000924

Fydrich, T., Sommer, G., \& Braehler, E. (2007). F-SOZU Fragebogen zur sozialen

Unterstuetzung. Diagnostische Verfahren in der Psychotherapie. 
Galea, S., Merchant, R. M., \& Lurie, N. (2020). The Mental Health Consequences of COVID-19 and Physical Distancing. JAMA Internal Medicine.

https://doi.org/10.1001/jamainternmed.2020.1562

Gloster, A. T., Lamnisos, D., Lubenko, J., Presti, G., Squatrito, V., Constantinou, M., ... Karekla, M. (2020). Impact of COVID-19 pandemic on mental health: An international study. PLoS ONE, 15(12 December), 1-20.

https://doi.org/10.1371/journal.pone.0244809

Hao, F., Tan, W., Jiang, L., Zhang, L., Zhao, X., Zou, Y., \& Hu, Y. (2020). Since January 2020 Elsevier has created a COVID-19 resource centre with free information in English and Mandarin on the novel coronavirus COVID- 19. The COVID-19 resource centre is hosted on Elsevier Connect, the company's public news and information, (January).

Hayes, N., \& Joseph, S. (2003). Big 5 correlates of three measures of subjective wellbeing. Personality and Individual Differences. https://doi.org/10.1016/S01918869(02)00057-0

Hensley, L., \& Varela, R. E. (2008). PTSD symptoms and somatic complaints following Hurricane Katrina: The roles of trait anxiety and anxiety sensitivity. Journal of Clinical Child and Adolescent Psychology. https://doi.org/10.1080/15374410802148186

Hoefnagels, C., Meesters, C., \& Simenon, J. (2007). Social support as predictor of psychopathology in the adolescent offspring of psychiatric patients. Journal of Child and Family Studies, 16(1), 87-97. https://doi.org/10.1007/s10826-006$9070-9$

Holt-Lunstad, J., Smith, T. B., Baker, M., Harris, T., \& Stephenson, D. (2015). Loneliness and Social Isolation as Risk Factors for Mortality: A Meta-Analytic Review. Perspectives on Psychological Science, 10(2), 227-237. 
https://doi.org/10.1177/1745691614568352

Holt-Lunstad, J., Smith, T. B., \& Layton, J. B. (2010). Social relationships and mortality risk: A meta-analytic review. PLoS Medicine, 7(7).

https://doi.org/10.1371/journal.pmed.1000316

Jakubiak, B. K., \& Feeney, B. C. (2019). Interpersonal touch as a resource to facilitate positive personal and relational outcomes during stress discussions. Journal of Social and Personal Relationships, 36(9), 2918-2936.

https://doi.org/10.1177/0265407518804666

Kaye-Kauderer, H., Feingold, J. H., Feder, A., Southwick, S., \& Charney, D. (2021).

Resilience in the age of COVID-19, 1-13. https://doi.org/10.1192/bja.2021.5

Keep mental health in mind. (2020). Nature Medicine, 26(5), 631.

https://doi.org/10.1038/s41591-020-0914-4

Kendler, K. S., Gatz, M., Gardner, C. O., \& Pedersen, N. L. (2006). Personality and Major Depression: A Swedish Longitudinal, Population-Based Twin Study. Archives of General Psychiatry, 63(10), 1113-1120.

https://doi.org/10.1001/archpsyc.63.10.1113

Kendler, K. S., Karkowski, L. M., \& Prescott, C. A. (1999). Causal relationship between stressful life events and the onset of major depression. American Journal of Psychiatry, 156(6), 837-841. https://doi.org/10.1176/ajp.156.6.837

Kim, A. W., Nyengerai, T., \& Mendenhall, E. (2020). Evaluating the mental health impacts of the COVID-19 Pandemic: Perceived risk of COVID-19 infection and childhood trauma predict adult depressive symptoms in Urban South Africa.

Psychological Medicine. https://doi.org/10.1017/S0033291720003414

Kircher, T., Wöhr, M., Nenadic, I., Schwarting, R., Schratt, G., Alferink, J., ...

Dannlowski, U. (2018). Neurobiology of the major psychoses $\square$ : a translational perspective on brain structure and function — the FOR2107 consortium. 
European Archives of Psychiatry and Clinical Neuroscience, $O(0), 0$.

https://doi.org/10.1007/s00406-018-0943-x

Köhler, C. A., Evangelou, E., Stubbs, B., Solmi, M., Veronese, N., Belbasis, L., ...

Carvalho, A. F. (2018). Mapping risk factors for depression across the lifespan:

An umbrella review of evidence from meta-analyses and Mendelian

randomization studies. Journal of Psychiatric Research.

https://doi.org/10.1016/j.jpsychires.2018.05.020

Lahey, B. B. (2009). Public Health Significance of Neuroticism. American

Psychologist. https://doi.org/10.1037/a0015309

Lakey, B., \& Orehek, E. (2011). Relational Regulation Theory: A New Approach to

Explain the Link Between Perceived Social Support and Mental Health.

Psychological Review, 118(3), 482-495. https://doi.org/10.1037/a0023477

Laux, L., Glanzmann, P., Schaffner, P., \& Spielberger, C. (1981). Das State-Trait

Angstinventar. Weinheim (GER): Beltz.

Lehrl, S. (2005). Mehrfachwahl-Wortschatz-Intelligenztest MWT-B. Erlangen:

Straube.

Leppert, K., Koch, B., Brähler, E., \& Strauß, B. (2008). Die Resilienzskala (RS) -

Überprüfung der Langform RS-25 und einer Kurzform RS-13. Klinische

Diagnostik Und Evaluation, 1(2), 226-243. Retrieved from

https://www.researchgate.net/profile/Elmar_Braehler/publication/215985290_Die

_Resilienzskala_RS_-_Uberprufung_der_Langfrom_RS-

25_und_einer_Kurzform_RS-13/links/0046352c9279e95090000000/Die-

Resilienzskala-RS-Ueberpruefung-der-Langfrom-RS-25-und-einer-Kurzf

Loades, M. E., Chatburn, E., Higson-Sweeney, N., Reynolds, S., Shafran, R.,

Brigden, A., ... Crawley, E. (2020). Rapid Systematic Review: The Impact of

Social Isolation and Loneliness on the Mental Health of Children and 
Adolescents in the Context of COVID-19. Journal of the American Academy of Child and Adolescent Psychiatry. https://doi.org/10.1016/j.jaac.2020.05.009

Luo, M., Guo, L., Yu, M., \& Wang, H. (2020). The psychological and mental impact of coronavirus disease 2019 (COVID-19) on medical staff and general public - A systematic review and meta-analysis. Psychiatry Research.

https://doi.org/10.1016/j.psychres.2020.113190

Malouff, J. M., Thorsteinsson, E. B., \& Schutte, N. S. (2005). The relationship between the five-factor model of personality and symptoms of clinical disorders: A meta-analysis. Journal of Psychopathology and Behavioral Assessment. https://doi.org/10.1007/s10862-005-5384-y

Mancini, A. D. (2020). Heterogeneous Mental Health Consequences of COVID-19: Costs and Benefits. Psychological Trauma: Theory, Research, Practice, and Policy, 12, 15-16. https://doi.org/10.1037/tra0000894

Marin, M. F., Lord, C., Andrews, J., Juster, R. P., Sindi, S., Arsenault-Lapierre, G., ... Lupien, S. J. (2011). Chronic stress, cognitive functioning and mental health. Neurobiology of Learning and Memory. https://doi.org/10.1016/j.nlm.2011.02.016 McGinty, E. E., Presskreischer, R., Anderson, K. E., Han, H., \& Barry, C. L. (2020). Psychological distress and covid-19-related stressors reported in a longitudinal cohort of US adults in April and July 2020. JAMA - Journal of the American Medical Association. https://doi.org/10.1001/jama.2020.21231

Navrady, L. B., Adams, M. J., Chan, S. W. Y., Consortium, M. D. D. W. G. of the P. G., Ritchie, S. J., \& McIntosh, A. M. (2017). Genetic risk of major depressive disorder: the moderating and mediating effects of neuroticism and psychological resilience on clinical and self-reported depression. Psychological Medicine, 110. https://doi.org/10.1017/S0033291717003415

Nelson, J., Klumparendt, A., Doebler, P., \& Ehring, T. (2017). Childhood 
maltreatment and characteristics of adult depression: Meta-analysis. British

Journal of Psychiatry, 210(2), 96-104. https://doi.org/10.1192/bjp.bp.115.180752

Norbeck, J. S. (1984). Modification of Life Event Questionnaires for Use with Female

Respondents. Research in Nursing \& Health.

https://doi.org/10.1002/nur.4770070110

Ong, A. D., Bergeman, C. S., Bisconti, T. L., \& Wallace, K. A. (2006). Psychological

resilience, positive emotions, and successful adaptation to stress in later life.

Journal of Personality and Social Psychology, 91(4), 730-749.

https://doi.org/10.1037/0022-3514.91.4.730

Ozbay, F., Fitterling, H., Charney, D., \& Southwick, S. (2008). Social support and resilience to stress across the life span: A neurobiologic framework. Current Psychiatry Reports, 10(4), 304-310. https://doi.org/10.1007/s11920-008-0049-7

Parrish, E. (2020). The next pandemic: COVID-19 mental health pandemic.

Perspectives in Psychiatric Care. https://doi.org/10.1111/ppc.12571

Prati, G., \& Mancini, A. D. (2021). The Psychological Impact of COVID-19 Pandemic

Lockdowns: A Review and Meta-Analysis of Longitudinal Studies and Natural

Experiments. Psychological Medicine, 8-11.

https://doi.org/10.1017/S0033291721000015

Qiu, Q., Qian, S., Li, J., Jia, R., Wang, Y., \& Xu, Y. (2020). Risk factors for depressive symptoms among Chinese older adults: a meta-analysis. Journal of Affective

Disorders. https://doi.org/https://doi.org/10.1016/j.jad.2020.08.036

R Core Team (2020). (2020). R: A language and environment for statistical

computing. R: A Language and Environment for Statistical Computing. $R$

Foundation for Statistical Computing, Vienna, Austria.

Rasic, D., Hajek, T., Alda, M., \& Uher, R. (2014). Risk of mental illness in offspring of parents with schizophrenia, bipolar disorder, and major depressive disorder: A 
meta-analysis of family high-risk studies. Schizophrenia Bulletin, 40(1), 28-38.

https://doi.org/10.1093/schbul/sbt114

Ravi Philip Rajkumar. (2020). COVID-19 and mental health: A review of the existing literature. Asian Journal of Psychiatry, 52(January), 102066.

Reger, M. A., Stanley, I. H., \& Joiner, T. E. (2020). Suicide Mortality and Coronavirus Disease 2019 - A Perfect Storm? JAMA Psychiatry. https://doi.org/10.1001/jamapsychiatry.2020.1060

Riehm, K. E., Brenneke, S. G., Adams, L. B., Gilan, D., Lieb, K., Kunzler, A. M., ... Thrul, J. (2020). Association between psychological resilience and changes in mental distress during the COVID-19 pandemic. Journal of Affective Disorders. https://doi.org/10.1016/j.jad.2020.12.071

Rosebrock, L., Cernis, E., Lambe, S., Waite, F., Rek, S., Petit, A., ... Freeman, D. (2021). Catastrophic Cognitions about Coronavirus: The Oxford Psychological Investigation of Coronavirus Questionnaire [TOPIC-Q]. Psychological Medicine. https://doi.org/10.1017/S0033291721000283

Russell, D., Peplau, L. A., \& Cutrona, C. E. (1980). The revised UCLA Loneliness

Scale: Concurrent and discriminant validity evidence. Journal of Personality and Social Psychology. https://doi.org/10.1037/0022-3514.39.3.472

Saltzman, L. Y., Hansel, T. C., \& Bordnick, P. S. (2020). Loneliness, Isolation, and Social Support Factors in Post-COVID-19 Mental Health. Psychological Trauma:

Theory, Research, Practice, and Policy, 12, 55-57.

https://doi.org/10.1037/tra0000703

Schlotz, W., Schulz, P., Hellhammer, J., Stone, A. A., \& Hellhammer, D. H. (2006). Trait anxiety moderates the impact of performance pressure on salivary cortisol in everyday life. Psychoneuroendocrinology, 31(4), 459-472.

https://doi.org/10.1016/j.psyneuen.2005.11.003 
Shanahan, L., Steinhoff, A., Bechtiger, L., Murray, A. L., Nivette, A., Hepp, U., ... Eisner, M. (2020). Emotional Distress in Young Adults During the COVID-19 Pandemic: Evidence of Risk and Resilience From a Longitudinal Cohort Study. Psychological Medicine, 1-32. https://doi.org/10.1017/S003329172000241X

Shi, L., Lu, Z. A., Que, J. Y., Huang, X. L., Liu, L., Ran, M. S., ... Lu, L. (2020). Prevalence of and Risk Factors Associated With Mental Health Symptoms Among the General Population in China During the Coronavirus Disease 2019 Pandemic. JAMA Network Open, 3(7), e2014053.

https://doi.org/10.1001/jamanetworkopen.2020.14053

Sommerlad, A., Marston, L., Huntley, J., Livingston, G., Lewis, G., Steptoe, A., \& Fancourt, D. (2021). Social relationships and depression during the COVID-19 lockdown: Longitudinal analysis of the COVID-19 social study. Psychological Medicine. https://doi.org/10.1017/S0033291721000039

Tanaka, T., \& Okamoto, S. (2021). Increase in suicide following an initial decline during the COVID-19 pandemic in Japan. Nature Human Behaviour. https://doi.org/10.1038/s41562-020-01042-z

Teicher, M. H., \& Samson, J. A. (2013). Childhood maltreatment and psychopathology: A case for ecophenotypic variants as clinically and neurobiologically distinct subtypes. American Journal of Psychiatry, 170(10), 1114-1133. https://doi.org/10.1176/appi.ajp.2013.12070957

Thomas, P. A., \& Kim, S. (2020). Lost Touch? Implications of Physical Touch for Physical Health. The Journals of Gerontology: Series $B, X X(X \mathrm{x}), 1-5$. https://doi.org/10.1093/geronb/gbaa134

Tondo, L., Burrai, C., Scamonatti, L., Weissenburger, J., \& Rush, A. J. (1988). Comparison between clinician-rated and self-reported depressive symptoms in italian psychiatric patients. Neuropsychobiology. 
https://doi.org/10.1159/000118423

Varatharaj, A., Thomas, N., Ellul, M. A., Davies, N. W. S., Pollak, T. A., Tenorio, E. L., ... Plant, G. (2020). Neurological and neuropsychiatric complications of COVID-19 in 153 patients: a UK-wide surveillance study. The Lancet Psychiatry, O(0). https://doi.org/10.1016/S2215-0366(20)30287-X

Veer, I. M., Riepenhausen, A., Zerban, M., Wackerhagen, C., Puhlmann, L. M. C., Engen, H., ... Kalisch, R. (2021). Psycho-social factors associated with mental resilience in the Corona lockdown. Translational Psychiatry, 11(1). https://doi.org/10.1038/s41398-020-01150-4

Vindegaard, N., \& Benros, M. E. (2020). COVID-19 pandemic and mental health consequences: Systematic review of the current evidence. Brain, Behavior, and Immunity. https://doi.org/10.1016/j.bbi.2020.05.048

Wang, D., Hu, B., Hu, C., Zhu, F., Liu, X., Zhang, J., ... Peng, Z. (2020). Clinical Characteristics of 138 Hospitalized Patients with 2019 Novel CoronavirusInfected Pneumonia in Wuhan, China. JAMA - Journal of the American Medical Association. https://doi.org/10.1001/jama.2020.1585

Wang, J., Lloyd-Evans, B., Giacco, D., Forsyth, R., Nebo, C., Mann, F., \& Johnson, S. (2017). Social isolation in mental health: a conceptual and methodological review. Social Psychiatry and Psychiatric Epidemiology, 52(12), 1451-1461. https://doi.org/10.1007/s00127-017-1446-1

Wickham, H. (2018). ggplot2: Create Elegant Data Visualisations Using the Grammar of Graphics.

Wingenfeld, K., Spitzer, C., Mensebach, C., Grabe, H. J., Hill, A., Gast, U., ...

Driessen, M. (2010). Die deutsche Version des Childhood Trauma Questionnaire ( CTQ ): Erste Befunde zu den psychometrischen Kennwerten The German Version of the Childhood Trauma Questionnaire ( CTQ ): Preliminary 
Psychometric Properties. Psychotherapie, Psychosomatik, Medizinische

Psychologie, 60(11), 442-450.

Xiong, J., Lipsitz, O., Nasri, F., Lui, L. M. W., Gill, H., Phan, L., ... Mclntyre, R. S.

(2020). Impact of COVID-19 pandemic on mental health in the general

population: A systematic review. Journal of Affective Disorders.

https://doi.org/10.1016/j.jad.2020.08.001

Yip, P. S. F., Cheung, Y. T., Chau, P. H., \& Law, Y. W. (2010). The impact of epidemic outbreak: The case of severe acute respiratory syndrome (SARS) and suicide among older adults in Hong Kong. Crisis. https://doi.org/10.1027/0227$5910 / a 000015$ 


\section{Tables}

Table 1: Baseline variables collected between 2014-2018 associated with mental health outcomes

\begin{tabular}{|c|c|c|}
\hline Trait & Measure used & $\begin{array}{l}\text { References linking trait with } \\
\text { mental health outcome }\end{array}$ \\
\hline Childhood maltreatment & $\begin{array}{l}\text { Childhood Trauma } \\
\text { Questionnaire }\end{array}$ & $\begin{array}{l}\text { (Köhler et al., 2018; Nelson, } \\
\text { Klumparendt, Doebler, \& Ehring, } \\
\text { 2017; Teicher \& Samson, 2013) }\end{array}$ \\
\hline Familial risk & Self-report questionnaire & $\begin{array}{l}\text { (Rasic, Hajek, Alda, \& Uher, } \\
\text { 2014) }\end{array}$ \\
\hline Social support & FSozu & $\begin{array}{l}\text { (Lakey \& Orehek, 2011; Ozbay, } \\
\text { Fitterling, Charney, \& Southwick, } \\
\text { 2008) }\end{array}$ \\
\hline Resilience & RS-25 & $\begin{array}{l}\text { (Navrady et al., 2017; Ong, } \\
\text { Bergeman, Bisconti, \& Wallace, } \\
\text { 2006) }\end{array}$ \\
\hline IQ & MWTB & (Der, Batty, \& Deary, 2009) \\
\hline Trait anxiety & STAI-T & $\begin{array}{l}\text { (Chambers, Power, \& Durham, } \\
\text { 2004; Schlotz, Schulz, } \\
\text { Hellhammer, Stone, \& } \\
\text { Hellhammer, 2006) }\end{array}$ \\
\hline Openness & NEOFFI & (DeNeve \& Cooper, 1998) \\
\hline Conscientiousness & NEOFFI & $\begin{array}{l}\text { (DeNeve \& Cooper, 1998; Hayes } \\
\text { \& Joseph, 2003; Malouff, } \\
\text { Thorsteinsson, \& Schutte, 2005) } \\
\text { (DeNeve \& Cooper, 1998; Hayes }\end{array}$ \\
\hline Extraversion & NEOFFI & $\begin{array}{l}\text { \& Joseph, 2003; Malouff et al., } \\
\text { 2005) }\end{array}$ \\
\hline Agreeableness & NEOFFI & $\begin{array}{l}\text { (DeNeve \& Cooper, 1998; } \\
\text { Malouff et al., 2005) }\end{array}$ \\
\hline Neuroticism & NEOFFI & $\begin{array}{l}\text { (DeNeve \& Cooper, 1998; Hayes } \\
\text { \& Joseph, 2003; Kendler et al., } \\
\text { 2006; Lahey, 2009; Malouff et al., } \\
\text { 2005; Navrady et al., 2017) }\end{array}$ \\
\hline
\end{tabular}

Note: References for the individual measures used can be found in the method section

of the manuscript. Mental health outcomes included associations with subjective wellbeing, happiness, depressive symptoms, and MDD. 
Table 2: Sample characteristics at baseline collected 2014-2018 before the COVID-

19 pandemic

\begin{tabular}{|c|c|c|c|c|}
\hline & $\begin{array}{l}\text { Whole sample } \\
\text { M (SD) }\end{array}$ & $\begin{array}{l}\text { Healthy } \\
\text { participants } \\
\text { M (SD) }\end{array}$ & $\begin{array}{l}\text { Patients } \\
\mathrm{M}(S D)\end{array}$ & $\begin{array}{l}\text { Difference } \\
\text { (p-value) }\end{array}$ \\
\hline $\mathrm{N}$ & 1268 & 622 & 646 & \\
\hline Age & $37.20(13.40)$ & $36.11(13.53)$ & $38.25(13.20)$ & $p=.004^{\star}$ \\
\hline Sex $f / m$ & $831 / 437$ & $404 / 218$ & $427 / 219$ & $p=.667$ \\
\hline $\begin{array}{l}\text { Childhood maltreatment } \\
\text { (CTQ sum score) }\end{array}$ & 38.48 (13.69) & 32.57 (8.39) & $44.16(15.31)$ & $p<.001^{*}$ \\
\hline $\begin{array}{l}\text { Familial risk } \\
\text { With risk/Without risk }\end{array}$ & $345 / 923$ & $133 / 489$ & $212 / 434$ & $p<.001^{*}$ \\
\hline Social support (FSozu) & $4.19(0.76)$ & $4.51(0.52)$ & $3.87(0.82)$ & $p<.001^{*}$ \\
\hline Resilience (RS-25) & $128.01(25.85)$ & $141.83(17.96)$ & 114.65 (25.29) & $p<.001^{*}$ \\
\hline IQ (MWT-B) & $115.14(13.78)$ & $115.86(13.48)$ & $114.44(14.03)$ & $p=.067$ \\
\hline Trait anxiety (STAI-T) & $42.36(13.78)$ & 33.33 (8.23) & $51.08(12.38)$ & $p<.001^{*}$ \\
\hline Openness (NEO-FFI) & 30.37 (6.76) & 30.69 (6.63) & 30.07 (6.86) & $p=.112$ \\
\hline $\begin{array}{l}\text { Conscientiousness } \\
\text { (NEO-FFI) }\end{array}$ & $32.39(7.14)$ & $34.65(6.37)$ & $30.21(7.17)$ & $p<.001^{*}$ \\
\hline Extraversion (NEO-FFI) & 26.82 (8.01) & 30.88 (6.06) & 22.93 (7.72) & $p<.001^{*}$ \\
\hline $\begin{array}{l}\text { Agreeableness } \\
\text { (NEO-FFI) }\end{array}$ & 33.59 (5.93) & $35.04(5.49)$ & $32.20(6.014)$ & $p<.001^{*}$ \\
\hline Neuroticism (NEO-FFI) & $21.53(10.30)$ & $15.20(7.39)$ & 27.60 (8.95) & $p<.001^{\star}$ \\
\hline
\end{tabular}


Table 3: Health and life changes due to Covid-19. Data collected April/May 2020 during lockdown.

\begin{tabular}{|c|c|c|c|}
\hline & $\begin{array}{l}\text { Whole } \\
\text { sample } \\
N=1268\end{array}$ & $\begin{array}{l}\text { Healthy } \\
\text { participants } \\
n=622\end{array}$ & $\begin{array}{l}\text { Patients } \\
n=646\end{array}$ \\
\hline Covid-19 health concerns & $\mathrm{N}(\%)$ & $\mathrm{n}(\%)$ & $\mathrm{n}(\%)$ \\
\hline $\begin{array}{l}\text { Personally, or associated person in } \\
\text { contact with Covid-19 positive } \\
\text { person }\end{array}$ & $214(16.9 \%)$ & $127(20.0 \%)$ & $87(13.5 \%)$ \\
\hline $\begin{array}{l}\text { Personally, or associated person in } \\
\text { mandated quarantine }\end{array}$ & $236(18.6 \%)$ & $120(19.3 \%)$ & $116(18.0 \%)$ \\
\hline $\begin{array}{l}\text { Personally, or associated person } \\
\text { tested positive for Covid-19 }\end{array}$ & $52(4.1 \%)$ & $26(4.2 \%)$ & $26(4.0 \%)$ \\
\hline $\begin{array}{l}\text { Personally tested positive for Covid- } \\
19\end{array}$ & $5(0.4 \%)$ & $3(0.2 \%)$ & $2(0.3 \%)$ \\
\hline $\begin{array}{l}\text { Personally, or associated person in- } \\
\text { patient treatment }\end{array}$ & $6(0.5 \%)$ & $5(0.8 \%)$ & $1(0.2 \%)$ \\
\hline $\begin{array}{l}\text { Intensive care treatment of self or } \\
\text { close one }\end{array}$ & $5(0.4 \%)$ & $4(0.6 \%)$ & $1(0.2 \%)$ \\
\hline $\begin{array}{l}\text { Death of associated person due to } \\
\text { Covid-19 }\end{array}$ & $4(0.3 \%)$ & $3(0.5 \%)$ & $1(0.2 \%)$ \\
\hline Covid-19-related incidents & $\mathrm{M}(S D)$ & $\mathrm{M}(S D)$ & $\mathrm{M}(S D)$ \\
\hline $\begin{array}{l}\text { Number of events experienced } \\
\text { (range: } 0-11 \text { ) }\end{array}$ & $3.04(1.68)$ & $3.09(1.60)$ & $2.99(1.76)$ \\
\hline $\begin{array}{l}\text { Negative Covid-19 impact rating } \\
\text { (range: } 0-55 \text { ) }\end{array}$ & $6.60(5.21)$ & $6.84(5.03)$ & $6.36(5.38)$ \\
\hline $\begin{array}{l}\text { Positive Covid-19 impact rating } \\
\text { (range: } 0-55 \text { ) }\end{array}$ & 0.97 (2.12) & $0.98(2.02)$ & $0.96(2.21)$ \\
\hline $\begin{array}{l}\text { Total Covid-19 impact (range: } 0 \text { - } \\
55 \text { ) }\end{array}$ & $7.56(5.64)$ & $7.82(5.46)$ & $7.32(5.81)$ \\
\hline
\end{tabular}

Table 4: Subjective Covid-19-related distress

\begin{tabular}{lllll} 
& Whole & HC & Patients & p-Value \\
& sample & & & \\
\hline Subjective fear (range 0-30) & $13.18(5.27)$ & $12.96(4.89)$ & $13.39(5.60)$ & $p=.152$ \\
Subjective isolation (range: 3-12) & $5.34(2.20)$ & $4.73(1.77)$ & $5.93(2.41)$ & $\begin{array}{l}p<.001 \\
\text { * }\end{array}$ \\
& & & &
\end{tabular}


Table 5: Changes in illness severity and treatment obstacles during pandemic in

patients. Data collected April/May 2020 during lockdown.

Symptoms and care

Sum $\%$ of patients

Subjective symptoms in January 2020 (before pandemic lockdown)

"No, I was fine"

$330 \quad 51.1 \%$

"Yes, mildly affected"

$190 \quad 29.4 \%$

"Yes, strongly affected"

$110 \quad 17.0 \%$

Change in symptom severity since beginning of the pandemic

Unchanged

A little worse

Substantially worse

Improved

Experienced Covid-19-related obstacles in treatment options

Problems in obtaining medication

Problems in obtaining social psychiatric aid

Changes in therapy

Other changes
$373 \quad 59.2 \%$

$133 \quad 21.1 \%$

$59 \quad 9.4 \%$

$65 \quad 10.3 \%$

$176 \quad 27.9 \%$

$18 \quad 2.8 \%$

$45 \quad 7.1 \%$

$138 \quad 21.4 \%$

$35 \quad 5.4 \%$

Data were missing for $n=16$ patients 
Table 6: Patients grouped according to symptom changes since the pandemic

Changes in symptom

Unchanged Worsened Improved

difference

severity from January to

(p-value)

April/May 2020

Total $n$

373

192

65

\section{Baseline data}

$\operatorname{Sex}(\mathrm{f} / \mathrm{m})$

Trait anxiety

Conscientiousness

Social support
$226 / 147$

49.95 (12.87)

30.68 (6.96)

3.89 (0.84)
$143 / 49$

$53.82(10.67)$

$29.53(7.61)$

$3.76(0.81)$
$49 / 16$

50.27 (12.88)

$29.51(7.32)$

4.02 (0.69)

$p=.001^{*}$

$p=.002$

$p=.148$

$p=.054$

$p=.755$

297

42

12

22

155

49

9

4

3

21

9

7

Remission state at baseline $\mathbf{n}^{1}$

Acute

134

$p=.334$

Partial Remission

88

84

23

Full Remission/Symptom 129

44

17

53

18

free

\section{Psychiatric comorbidity}

at baseline $\mathbf{n}$

None

243

At least one

130

102

36

29

90

$$
p=.099
$$

Recurrence status MDD

45

18

187

$p=.015^{\star}$

Single Episode 113
31

Note: $p$-Values indicate results for Chi-Square test or ANOVA. Symptom change data were missing for $n=16$ patients. Stars indicate significance at $p<.05$. 1) Data were missing for $n=42$ participants 
Table 6 Cont.: Patients grouped according to symptom changes since the pandemic

Changes in symptom

Unchanged Worsened Improved

difference

severity from January to

(p-value)

April/May 2020

\section{Covid-19 data}

\begin{tabular}{|c|c|c|c|c|}
\hline $\begin{array}{l}\text { Number of experienced } \\
\text { Covid-19 incidents } n(S D)\end{array}$ & $2.84(1.66)$ & $3.22(1.81)$ & $3.12(1.85)$ & $p=.095$ \\
\hline $\begin{array}{l}\text { Negative Covid-19 impact } \\
\text { rating }\end{array}$ & $5.64(4.76)$ & $7.84(5.56)$ & $5.63(5.54)$ & $p<.001^{*}$ \\
\hline $\begin{array}{l}\text { Positive Covid-19 impact } \\
\text { rating }\end{array}$ & $1.01(2.33)$ & $0.63(1.36)$ & $1.45(2.59)$ & $p=.017^{\star}$ \\
\hline Total Covid-19 Impact & $6.64(5.12)$ & $8.47(5.63)$ & $7.08(6.77)$ & $\mathrm{p}=.001^{*}$ \\
\hline Subjective fear & $12.83(5.21)$ & $14.84(6.09)$ & $12.28(5.47)$ & $p<.001^{*}$ \\
\hline Subjective isolation & $5.35(2.18)$ & $7.11(2.44)$ & $5.95(2.29)$ & $p<.001^{\star}$ \\
\hline $\begin{array}{l}\text { Experienced Covid-19- } \\
\text { related constraints in } \\
\text { treatment options } n\end{array}$ & 78 & 79 & 19 & $p<.001^{*}$ \\
\hline $\begin{array}{l}\text { Problems obtaining } \\
\text { medication }(n)\end{array}$ & 6 & 12 & 0 & $p=.003^{\prime}$ \\
\hline $\begin{array}{l}\text { Problems obtaining social } \\
\text { psychiatric aid }(n)\end{array}$ & 19 & 18 & 8 & $p=.040$ \\
\hline Changes in therapy $(n)$ & 55 & 67 & 16 & $p<.001^{*}$ \\
\hline Other changes (n) & 15 & 16 & 4 & $p=.103$ \\
\hline
\end{tabular}


medRxiv preprint doi: https://doi.org/10.1101/2021.04.01.21254625; this version posted April 5, 2021. The copyright holder for this preprint (which was not certified by peer review) is the author/funder, who has granted medRxiv a license to display the preprint in perpetuity. It is made available under a CC-BY-NC-ND 4.0 International license. 